\title{
QUALITY ASSURANCE REQUIREMENTS FOR WATER-QUALITY LABORATORIES PROVIDING ANALYTICAL SERVICES FOR THE WATER RESOURCES DIVISION OF THE
}

\section{U.S. GEOLOGICAL SURVEY}

by David E. Erdmann

U.S. GEOLOGICAL SURVEY

Open-File Report 91-222

Denver, Colorado

1991

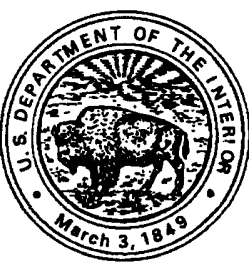




\section{U.S. DEPARTMENT OF THE INTERIOR \\ MANUEL LUJAN, JR., Secretary \\ U.S. GEOLOGICAL SURVEY \\ Dallas L. Peck, Director}

For additional information write to:

Chief, Branch of Quality Assurance U.S. Geological Survey Box 25046, Mail Stop 401 Federal Center Denver, CO 80225-0046
Copies of this report can be purchased from:

U.S. Geological Survey Books and Open-File Reports Section Box 25425, Mail Stop 517 Federal Center Denver, CO 80225-0425 
Table 1. The part of the Water Resources Division's organization applicable to this report- 2 


\title{
QUALITY ASSURANCE REQUIREMENTS FOR WATER-QUALITY LABORATORIES PROVIDING ANALYTICAL SERVICES FOR THE WATER RESOURCES DIVISION OF THE U.S. GEOLOGICAL SURVEY
}

By David E. Erdmann

\begin{abstract}
The quality assurance requirements for laboratories providing analytical services for the Water Resources Division of the U.S. Geological Survey are defined. The scope of requirements and responsibilities of various personnel, the Office of Water Quality, and the Branch of Quality Assurance within the Water Resources Division are discussed. Quality assurance plans, evaluation and quality assurance samples, and documentation that are required for hydrologic investigations including water-quality analyses are described.
\end{abstract}

\section{INTRODUCTION}

As part of the continuing effort to provide the public and local, State, and Federal agencies with accurate and precise hydrologic data, the Water Resources Division (WRD) of the U.S. Geological Survey (USGS) has established the Branch of Quality Assurance (BQA) (table 1). The primary function of the $B Q A$ is to develop protocols for the collection and analysis of accurate and precise hydrologic data. As part of this primary function, the BQA has the responsibility for developing quality assurance requirements for water-quality laboratories providing analytical services for the WRD of the USGS. All water-quality laboratories providing analytical data for storage in the National Water Data Storage and Retrieval System (WATSTORE) (Hutchison, 1975) of the USGS are subject to these quality assurance requirements.

This report documents the quality assurance requirements for all waterquality laboratories that provide analytical services for the WRD of the USGS resulting in data storage in WATSTORE. Procedures for the implementation of the quality assurance requirements by various personnel, the Office of Water Quality, and the BQA within the WRD are defined. The quality assurance requirements are designed to ensure that analytical data are accurate within objective measures of precision and that analytical standards (Friedman and Erdmann, 1982) of the USGS are maintained.

The quality assurance requirements automatically apply to all waterquality laboratories that provide more than $\$ 15,000$ worth of analytical services annually for the WRD. For those water-quality laboratories that provide $\$ 15,000$ or less of analytical services annually for the WRD, the BQA is to be contacted so that modified quality assurance requirements (not presented in this report because they are laboratory specific) can be developed. The BQA also will modify the quality assurance requirements documented in this report if the requirements do not adequately address the analytical determinations of interest. 
Table 1.--The part of the Water Resources Division's organization applicable to this report

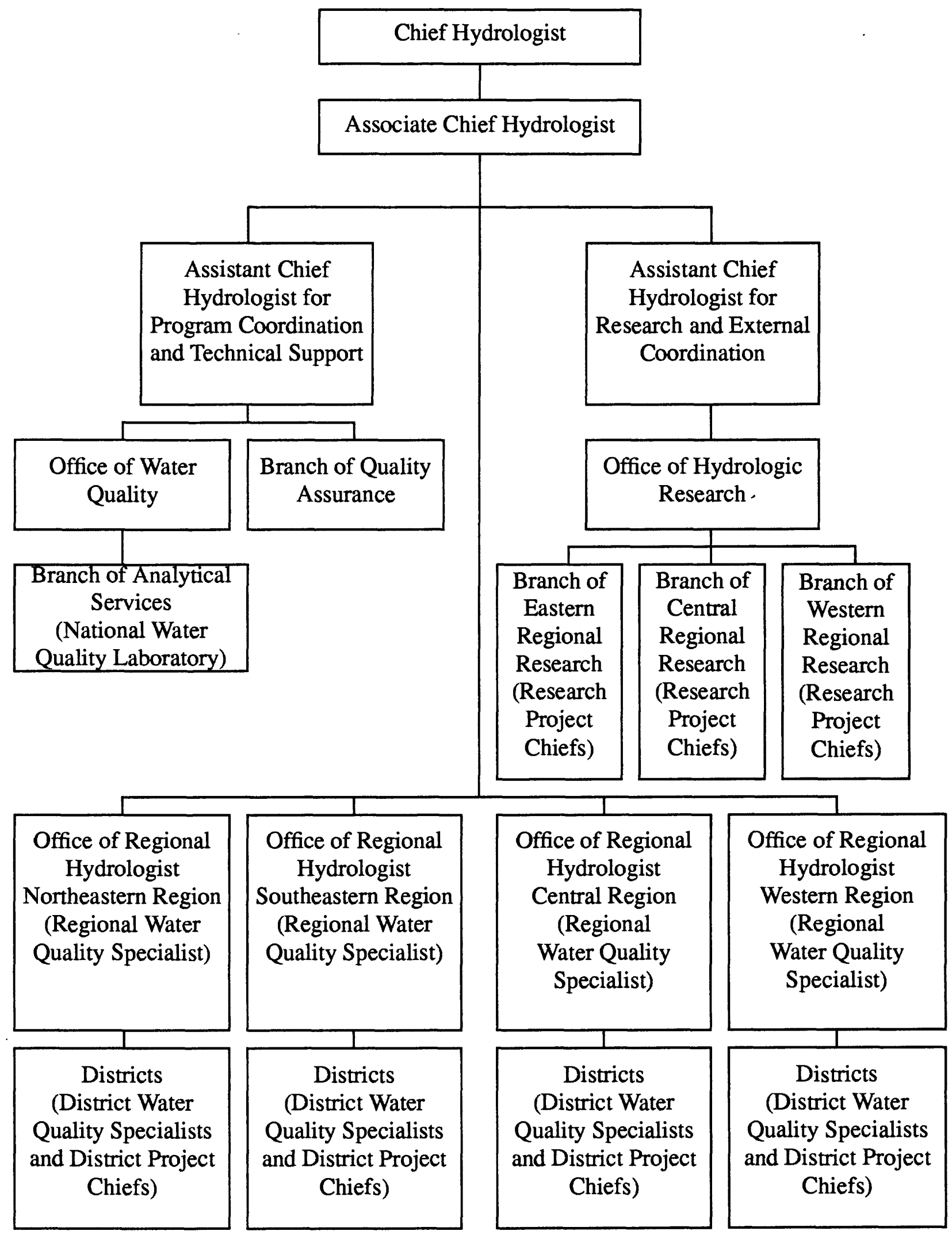




\section{DEFINITIONS}

- National Water Quality Laboratory (NWQL)--The WRD's principal analytical laboratory (table 1) located in Arvada, Colo. This laboratory analyzes environmental samples for a wide variety of inorganic and organic constituents.

- Internal laboratory--Any laboratory (other than the NWQL) being operated by WRD personnel. This category includes laboratories of personnel in the Branches of Regional Research, laboratories in District offices throughout the country, and field service units that determine field constituents such as $\mathrm{pH}$, specific conductance, and alkalinity.

External Laboratory--Any laboratory operated by non-WRD personne1. This category includes all water-quality laboratories other than the NWQL and internal laboratories; such as commercial laboratories, Geologic Division (USGS) laboratories, and cooperator (local, State, or Federal agencies) laboratories.

Standard Reference Water Sample (SRWS) Program--The WRD's interlaboratory evaluation program (Janzer, 1985).

WATSTORE--The national data base of the WRD. The WATSTORE data base is located in Reston, Va., and contains extensive surface-water, waterquality, and ground-water information from throughout the United States.

Environmental samples--Representative portions of environmental materials that are collected for characterization or analysis.

Performance-evaluation samples--Well-characterized samples that are submitted to a laboratory, usually by an external organization, to determine its analytical competence.

Quality assurance samples

- Duplicate samples--Two samples collected in such a way that the samples are thought to be essentially identical in composition.

- Independent-standard solutions--Solutions prepared from reagents or concentrated standard solutions that are from a different lot or supplier than was used to prepare the calibration standards. These solutions are often used either to verify the calibration process or to monitor the stability of the analytical process.

- Spiked samples--Samples to which known concentrations of specific analytes have been added in such a manner as to minimize changes in matrix of the original samples.

- Reference samples--Samples one or more properties of which are sufficiently well established to be used for the assessment of a measurement method or for assigning values to analytes.

- Split samples--Types of replicate samples in which a sample is split into subsamples contemporaneous in time and space.

- Blank samples--Samples that are free of the analyte(s) of interest. 
- Research or District Project Chiefs (table 1) are responsible for requesting written approval to use any laboratory other than the NWQL from the Chief, Office of Water Quality (OWQ), prior to use of the laboratory; providing the $\mathrm{BQA}$ with a quality assurance/quality control plan obtained from internal or external water-quality laboratories providing analytical services for the WRD; ensuring that the laboratories have analyzed performance-evaluation samples and are participants in the SRWS Program, if appropriate; ensuring that approved analytical methods are used; submitting appropriate quality assurance samples and verifying that the laboratories use an adequate number and type of quality control materials; and participating in technical reviews of the laboratories (Erdmann, 1991).

The Research or District Project Chiefs have the primary responsibility for review and acceptance of analytical data generated in support of their hydrologic investigations. The Project Chiefs also are responsible for maintaining an up-to-date compilation and summary of the results from reference, duplicate, spike, and blank samples. In the event that sample or quality assurance analyses appear to be unsatisfactory, the District Water Quality Specialist (table 1), Regional Water Quality Specialist (table 1), and the $\mathrm{BQA}$ will be available for consultation regarding corrective actions.

- The BQA is responsible for: (1) Reviewing and approving the quality assurance/quality control plans of the water-quality laboratories; (2) evaluating results from the SRWS Program; (3) conducting technical reviews of laboratories; and (4) providing technical advice. Guidance also will be provided by the $B Q A$, if necessary, during the preparation of satisfactory quality assurance/quality control plans.

- The OWQ is responsible for approving laboratories that provide data for WRD programs and for approving analytical methods, when necessary.

\section{QUALITY ASSURANCE REQUIREMENTS AND ASSOCIATED PROCEDURES}

\section{Review and Approval of the Water-Quality Laboratory's Quality Assurance/Quality Control Plan}

The Research or District Project Chief will submit both a written request to the Chief, OWQ, for approval to use an internal or external laboratory and a copy of the laboratory's quality assurance/quality control plan to the BQA for review and approval. For external laboratories, both of these approvals shall be obtained before a cooperative or contractual agreement is signed. The quality assurance/quality control plan needs to address items such as organization, personnel, facilities, instrumentation, methods, standard operating procedures, calibration techniques, types of quality control samples used, documentation practices, data validation, use of quality control charts, and the chemical logic checks used to determine the acceptability of an analysis, such as the agreement between milliequivalents of anions and cations 
or the ratio between specific conductance and dissolved solids. The review of the laboratory's quality assurance/quality control plan will be expeditiously performed by the BQA and a notice of approval or disapproval, along with suggested modifications, will be returned to the Chief, OWQ, and the Project Chief. If the plan is disapproved, it will need to be modified before samples collected by the WRD can be analyzed. A new copy of the quality assurance/quality control plan is to be provided to the Project Chief by the laboratory whenever the plan is updated. The Research or District Project Chief will be notified by the Chief, OWQ, if a laboratory is approved or disapproved for use.

If an external laboratory is currently providing analytical services for the WRD under a previous agreement, the Project Chief is to forward the latest copy of the laboratory's quality assurance/quality control plan to the BQA. This plan will be reviewed and comments on the adequacy of the plan will be forwarded to the Project Chief.

\section{Analysis of Performance-Evaluation Samples}

Internal laboratories shall satisfactorily analyze a set of performanceevaluation samples, if available, before they begin analysis of environmental samples. Prior to the signing of a cooperative or contractual agreement, and analysis of environmental samples, an external laboratory shall satisfactorily analyze a set of performance-evaluation samples. As a preferable alternative, the laboratory could be a participant in the SRWS Program at the earliest indication that their services might be required in the future. A historical record of their capability would thus exist and a satisfactory performance in this program could be substituted for the required analysis of performanceevaluation samples. If additional types of determinations are required by the Research or District Project Chief after the hydrologic investigation has begun, performance-evaluation samples are to be satisfactorily analyzed for these determinations before environmental samples are analyzed.

\section{Preliminary Technical Review of the Water-Quality Laboratory}

If the value of analytical services to be performed by an internal or external laboratory is projected to exceed $\$ 15,000$ per year, a technical review of the laboratory shall be performed by the BQA before environmental samples are analyzed for the WRD. Usually, the Research or District Project Chief, District Water Quality Specialist, or other appropriate persons also will participate in the review. This review is to take place after the results of performance-evaluation samples are known in order to determine the strengths and weaknesses of the laboratory. A detailed discussion of the technical review is presented by Erdmann (1991).

\section{Use of Approved Analytical Methods}

Internal and external laboratories shall use approved analytical methods. A manual containing a detailed description of these methods is to be provided to the Research or District Project Chief by the laboratory. The methods 
included in the most recent editions of publications from the USGS, U.S. Environmental Protection Agency (USEPA), American Public Health Association and others, and American Society for Testing Materials are approved for use. Any method not included in one of these publications has to be approved by the Office of Water Quality (table 1) before the method is used to generate any analytical data for a WRD hydrologic investigation. Approved methods need to provide data that meet the requirements of the hydrologic investigation with regard to applications, detection limits, interferences, and so forth. The BQA will assist in the evaluation of a method as necessary. The Project Chief is to be notified of method changes by the laboratory when they occur, and the Project Chief and laboratory are to maintain a file of these changes so that a historical record of the use of the method is available.

\section{Participation in the Standard Reference Water Sample Program}

If inorganic constituents are to be determined, the Research or District Project Chief shall insure that all internal and external laboratories providing analytical services participate in the SRWS Program sponsored by the WRD. Laboratories determining organic constituents will be required to participate in the SRWS Program as soon as appropriate reference materials are prepared by the BQA. The constituents determined in the various SRWS's should correspond to those to be determined for the hydrologic investigation(s). The Research or District Project Chief shall encourage the laboratory to participate in other evaluation programs, such as those conducted by the USEPA. This is especially important if organic constituents are to be determined.

\section{Quality Assurance Samples and Blanks}

The following types of quality assurance samples shall be analyzed by internal and external laboratories: duplicate, independent standard, spiked, reference, and split. In addition, blanks also shall be analyzed.

Laboratory Duplicate, Independent-Standard, Reference, and Spiked Samples

A combination of duplicate, independent-standard, reference, and spiked samples are to be analyzed by internal and external laboratories as part of their quality control program. Internal or external laboratories are responsible for providing the Research or District Project Chief with statistical compilations of any quality control data of this type collected in association with analyses of environmental samples for the WRD. The duplicate, independent-standard, and spiked samples shall constitute at least 6 to 10 percent of the laboratory's workload.

\section{Reference Samples}

At least 3 to 5 percent of the samples sent by the Research or District Project Chief to the laboratory for analysis shall be reference samples. Although not always possible, it is highly desirable that the reference 
samples be submitted as blind samples (unknown to all laboratory personnel). The Project Chief can request inorganic reference samples from the BQA.

Samples provided by the BQA will include data on the most probable values and expected standard deviations for the analytes in the samples. Additional reference samples can be obtained from the USEPA or from commercial vendors. The analytical results for these samples shall be summarized and filed by the Project Chief.

\section{Split Samples}

At least 2 to 5 percent of the environmental samples collected by the Research or District Project Chief will be split into subsamples or split samples. If possible, these split samples are to be submitted to the internal or external laboratory as blind samples. A statistical measure of analytical precision can thus be obtained. If the Project Chief desires to check analytical capability of the laboratory, one of the split samples can be sent to another laboratory. After receipt and evaluation of the analytical results for split samples sent to two laboratories, reanalysis might be required from either or both laboratories in order to resolve any differences. The Project Chief shall keep a record of significant differences between the two analyses and shall decide which is the best value to enter into WATSTORE.

\section{Blanks}

Blanks commonly are submitted to the internal or external laboratory by the Research or District Project Chief in order to verify the lack of sample contamination during the sampling, sample-handling, and analytical processes. In general, more blanks will be required as the detection limit of an analytical method decreases because the effects of contamination generally become more important. The percentage of blanks should not be less than 1 percent of the samples submitted and might need to be as high as 10 percent for extremely sensitive analytical determinations.

\section{Percentage of Total Samples that are to be Quality Assurance Samples}

The combination of laboratory plus field quality assurance samples will typically constitute about 15 to 20 percent of the total samples analyzed for each analyte. The percentage will be considerably greater, however, if small sets of samples are routinely submitted, because it is important to have a minimum number of quality assurance samples in each set for verification and documentation purposes.

\section{Ongoing Technical Reviews of Water-Quality Laboratories}

Technical reviews of an internal or external laboratory providing analytical services for the WRD will be conducted on a regular and continuing basis by the BQA in order to confirm the effectiveness of the quality assurance program of the laboratory. Again, the Research or District Project Chief, District Water Quality Specialist, or other appropriate persons usually will participate in the technical reviews. 


\section{RECORDS MANAGEMENT}

The Research or District Project Chief will keep up-to-date copies of laboratory quality assurance/quality control plans from all internal and external laboratories performing analytical services for a hydrologic investigation. A current summary of results from quality assurance samples also shall be maintained by the Project Chief.

The BQA will prepare, distribute, and maintain copies of the technical reviews of internal and external laboratories as described in Erdmann (1991).

\section{REFERENCES CITED}

Erdmann, D.E., 1991, Technical review of water-quality laboratories providing analytical services for the Water Resources Division of the U.S. Geological Survey: U.S. Geological Survey Open-File Report 91-223, $19 \mathrm{p}$.

Friedman, L.C., and Erdmann, D.E., 1982, Quality-assurance practices for the chemical and biological analyses of water and fluvial sediments: U.S. Geological Survey Techniques of Water-Resources Investigations, book 5, chap. A6, $181 \mathrm{p}$.

Hutchison, N.E., 1975, WATSTORE - National water storage and retrieval system of the U.S. Geological Survey - user's guide (volume 1): U.S. Geological Survey Open-File Report 75-426, 565 p.

Janzer, V.J., 1985, The use of natural waters as U.S. Geological Survey reference materials: Special Testing Publication 867, Philadelphia, American Society for Testing and Materials, p. 319-333. 